Reprod. Nutr. Dévelop., 1988, 28 Suppl. n 1,73-74

\title{
Expression des gènes lors de l'induction des hydrolases chez Neocallimastix frontalis
}

\author{
Pascale REYMOND, M. FĖVRE
}

Laboratoire de Différenciation fongique, U.A. C.N.R.S. 1127, Bât. 405 , 43, bd du 11-Novembre 1918, 69622 Villeurbanne Cedex, France.

Summary. The secretion of inducible glucohydrolases by Neocallimastix frontalis is characterized by changes in the pattern of protein synthesis. SDS PAGE electrophoresis of extracellular proteins and of proteins specified by poly $A^{+}$RNA revealed the differential gene expression. Results suggest that it is feasable to clone genes expressed during culture conditions promoting secretion of glucohydrolases. A cDNA library from induced cultures was prepared and will allow the cloning of hydrolase genes.

Neocallimastix frontalis, champignon anaérobie du rumen, possède une panoplie d'enzymes capables de dégrader les parois cellulaires végétales. Ces enzymes inductibles sont caractérisées par une grande diversité, et une forte activité (1). Nous développons actuellement un programme de recherche en biologie moléculaire, afin de mieux comprendre le fonctionnement de ce système lytique. Les étapes indispensables au clonage des gênes d'hydrolases : construction d'une banque génomique, caractérisation des $A R N m$, et construction d'une banque d'ADN complémentaire, ont été réalisées.

Matériel et méthodes. $N$. frontalis est cultivé en anaérobie stricte à $39{ }^{\circ} \mathrm{C}$, dans des flacons contenant $500 \mathrm{ml}$ de milieu additionné d'avicel à $0,6 \%$ (induction des hydrolases), ou de xylose à $1 \%$ (répression des hydrolases). L'ADN total a été isolé selon la technique de Raeder et Broda (2), à partir de mycélium âgé de 3 jours. L'ARN total a été extrait en présence de thiocyanate de guanidium (3). Les ARN messagers poly $(A)^{+}$ont été purifiés sur colonne d'oligo-dt-cellulose, par chromatographie d'affinité (4).

Les protéines marquées à la ${ }^{35} \mathrm{~S}$ méthionine ont été synthétisées dans le système de traduction in vitro Wheat Germ (BRL), en présence d'acides aminés froids, d'ions $\mathrm{K}^{+}$et $\mathrm{Mg}^{++}$, et de $100 \mu \mathrm{ci}$ de ${ }^{35} \mathrm{~S}$ méthionine.

Les ADNc simple et double brin ont été synthétisés respectivement à l'aide de la réverse transcriptase $M-M L V$, et du système Ribonucléase $H / A D N$ polymérase d'E. coli, selon le protocole décrit par le fabricant (Amersham).

Résultats et discussion. L'analyse en SDS PAGE des protéines de Neocallimastix frontalis cultivé en présence d'avicel montre que l'induction d'enzymes lytiques est caractérisée par l'apparition de nouvelles protéines dans le milieu de culture. Ces résultats indiquent une modification de l'expression des gènes, et ont été confirmés lors de l'étude de la traduction in vitro des ARNm.

Caractérisation des ARNm et des produits de traduction. - Les ARNm ont été isolés à partir de mycélium cultivé en condition de répression ou d'induction 
de la synthèse des enzymes lytiques. La qualité des ARNm a été vérifiée par traduction in vitro grâce au système wheat germ. La stimulation du système de traduction en présence d'ARNm est de 5 à 20 fois supérieure à celle du témoin sans ARNm. L'électrophorèse en SDS PAGE des protéines marquées révélées par autoradiographie a indiqué la présence de bandes correspondant à des protéines d'une taille supérieure à $66 \mathrm{KDa}$, ce qui correspond à des ARNm d'une taille de $1,8 \mathrm{~Kb}$. La comparaison des profils protéiques correspondant à des ARNm induits et non induits pour la synthèse d'hydrolases, a révélé la présence de bandes caractéristiques de l'état induit.

L'expression différente des gènes au cours de l'induction de la sécrétion d'enzymes lytiques suggère qu'il est possible de cloner les gènes spécifiquement induits par des cultures en présence d'avicel. Nous avons alors réalisé une banque d'ADN complémentaire à partir d'ARN extrait de cultures induites.

Synthèse d'ADN complémentaire. - Les ADNc, simple et double brin, ont été synthétisés en présence de ${ }^{32} \mathrm{P}$-dCTp et séparés sur gel d'agarose alcalin. Leur taille varie entre 0,2 et $4 \mathrm{~Kb}$.

Construction d'une banque d'ADN complémentaire. - Les ADN complémentaires double brin ont été insérés au site Eco RI du phage $\lambda 1149$, après méthylation, addition de linkers et libération des extrémités cohésives EcoRI. Après packaging, les phages ont été utilisés pour infecter la souche $E$. coli C $600 \mathrm{Hfl}$. La banque d'ADNc est constituée de 200000 pfu.

Chez Neocallimastix, l'induction d'enzymes lytiques est caractérisée par l'expression différentielle de gènes. Des différences ont été observées au niveau des protéines produites in vivo et au niveau de celles synthétisées in vitro.

L'hybridation différentielle de la banque d'ADNc avec des ARNm provenant de cultures induites et réprimées pour la production d'enzymes lytiques, permettra d'isoler les clones contenant les gènes spécifiquement activés au cours de la production d'hydrolases. Cette analyse moléculaire est nécessaire pour étudier la complexité du système lytique de Neocallimastix frontalis (nombre de gènes, structure des gènes). L'isolement des gènes permettra aussi d'étudier leur expression éventuelle et la sécrétion d'hydrolases chez Aspergillus, par la technique de la transformation génétique.

(1) Hebraud M., Fèvre M., 1988. J. gen. Microbio/., 134, 1123-1129.

(2) Raeder U., Broda P., 1985. Letters Appl. Microbiol.. 1, 17-20.

(3) Chirgwin J. M., Przybyla A. E., Mac Donald R. J., Rutter W. J., 1979. Biochemistry, 24, 5294-5299

(4) Maniatis T., Fritsch E. F., Sambrock J., 1982. Molecular cloning. A laboratory handbook. Cold Spring Harbor, New York. 